DIGITALCOMMONS —@WAYNESTATE-
Clinical Research in Practice: The Journal of Team Hippocrates

Volume 5 | Issue 1

Article 14

2019

\title{
Outcomes of robotic-assisted laparoscopic prostatectomy versus open prostatectomy in surgical intervention of localized prostate cancer
}

Hojun Lee

Wayne State University School of Medicine, holee@med.wayne.edu

Brandon Ahlgren

Wayne State University School of Medicine, bahlgren@med.wayne.edu

Follow this and additional works at: https://digitalcommons.wayne.edu/crp

Part of the Medical Education Commons, and the Translational Medical Research Commons

\section{Recommended Citation}

LEE H, AHLGREN B. Informed Consent: Outcomes of robotic-assisted laparoscopic prostatectomy versus open prostatectomy in surgical intervention of localized prostate cancer. Clin. Res. Prac. 2019 Mar 26;5(1):eP1923. doi: 10.22237/crp/1553558460

This Informed Consent is brought to you for free and open access by the Open Access Journals at DigitalCommons@WayneState. It has been accepted for inclusion in Clinical Research in Practice: The Journal of Team Hippocrates by an authorized editor of DigitalCommons@WayneState. 


\title{
INFORMED CONSENT:
}

\section{Outcomes of robotic-assisted laparoscopic prostatectomy versus open prostatectomy in surgical intervention of localized prostate cancer}

HOJUN LEE, B.M.S., Wayne State University School of Medicine, holee@med.wayne.edu BRANDON AHLGREN, B.S., Wayne State University School of Medicine, bahlgren@med.wayne.edu

\begin{abstract}
An informed consent conversation regarding robotic-assisted laparoscopic prostatectomy versus open prostatectomy in patients with localized prostate cancer.
\end{abstract}

Keywords: $\quad$ robotic-assisted laparoscopic prostatectomy, open prostatectomy, localized prostate cancer, prostatectomy

\section{Clinical Context}

Our patient is a 65-year-old man who presented to the urology clinic due to an elevated PSA of 7.7ng/mL. He has no significant medical history. A pelvic MRI revealed an intermediate risk lesion in the right mid gland of the prostate. Using the MRI images, a prostate biopsy was performed revealing grade group 2 prostate cancer (Gleason score $3+4)$. A repeat PSA had risen to $10.1 \mathrm{ng} / \mathrm{mL}$ over a 2 -month period. The patient presented to the clinic to discuss the results of the biopsy. Due to the grade group of the prostate cancer and the relatively long life expectancy of the patient, definitive intervention was recommended. Different possible modalities of treatment were discussed with the patient, including radiation therapy and cryoablation, but ultimately surgical intervention via radical prostatectomy was recommended. The patient asked for some time to digest his new diagnosis and to think about his options because the information was overwhelming, and he was concerned about urinary incontinence and erectile dysfunction.

The patient returned to clinic three weeks after his biopsy review to discuss his thoughts on treatment. Together with the attending physician, the patient decided robotic-assisted laparoscopic prostatectomy would be the best option for him. However, he had some concerns about the robotic approach to the surgery and what that entailed. He stated, "I talked to a couple of my friends who were also diagnosed with prostate cancer and underwent open prostatectomies with good success. Why do you suggest a robotic surgery in comparison to an open procedure?" The patient's question led the team to discuss the differences between a robotic-assisted laparoscopic prostatectomy (RALP) versus an open radical prostatectomy also known as retropubic radical prostatectomy (RRP).

\section{Clinical Question}

In patients with localized prostate cancer, does RALP provide improved outcomes compared to open prostatectomy?

HOJUN LEE and BRANDON AHLGREN are students at the Wayne State University School of Medicine. 
LEE H, AHLGREN B. Informed Consent: Outcomes of robotic-assisted laparoscopic prostatectomy versus open prostatectomy in surgical intervention of localized prostate cancer. Clin. Res. Prac. 2019 Mar 26;5(1):eP1923. doi: $10.22237 / \mathrm{crp} / 1553558460$
Clinical Research in Practice

The Journal of Team Hippocrates

VOL 5 ISS 1 / eP1923 / MARCH 26, 2019

doi: $\underline{10.22237 / \mathrm{crp} / 1553558460}$

\title{
Related Literature
}

A literature review was performed by searching PubMed using the terms "robotic"[tiab] AND "open"[tiab] AND

"prostatectomy"[tiab] AND "prostate cancer"[tiab] which yielded 334 search results. Within these results, several meta-analyses relevant to the clinical question were found. There is a lack of high quality randomized controlled trials to answer the clinical question. Therefore, observational studies were included in the literature review. While oncologic effect is the main indication for a radical prostatectomy, other parameters such as perioperative and functional outcomes were important to our patient and thus were considered during the literature review. Of the papers published in the last 10 years, eleven were determined to be of high quality and relevance in answering our clinical question. These articles each measured a combination of oncologic, functional, and perioperative outcomes of RALP versus RRP.

Coughlin (2018) ${ }^{1}$ was the most recent randomized controlled trial published comparing RALP with RRP. A total of 326 men were enrolled in the study with strict exclusion criteria to only include men with localized prostate cancer. Patients were randomized to either RALP or RRP with data analysts and pathologists blinded to the treatment groups. Outcomes of oncologic results at 24 months post-procedure were evaluated. Oncologic outcomes at 6 and 12 months post-procedure were reported in an earlier publication. $\underline{2}$ Urinary incontinence and erectile dysfunction were assessed by validated scales. .4 Urinary and sexual function assessed by questionnaire scores were not significantly different between RALP and RRP at any time point post-procedure. Oncologic outcomes, defined by biochemical recurrence with a PSA of $0.2 \mathrm{ng} / \mathrm{mL}$, were significantly better with RALP compared to RRP in this study. However, the authors state that oncologic management post-procedure of enrolled patients was not controlled and a higher number of RALP patients received adjunctive radiotherapy prior to any PSA increases that may have affected this finding.

The next study was a retrospective cohort by $\mathrm{Hu}$, et. al. in 2017. $\underline{5}$ This was a study using a Medicare linked database. Two cohorts were propensity-matched and then compared; the first cohort having undergone RALP and the second having undergone an open prostatectomy. Both cohorts had the same risk of all-cause and cancer-specific mortality. Rates of complications were not investigated.

The 2016 study by O'Neil, et. al. was another retrospective cohort study. $\underline{6}$ It used two prospectively collected databases, which were collected almost two decades apart. Patients who had underwent RALP had improved sexual function at 6 and 12 months and improved urinary function at 6 months when compared to patients who underwent RRP. However, the improvement of urinary function was no longer present at 12 months.

The last primary research discovered was Haglind et. al. in 2015. ${ }^{-}$This was a prospective, multi-center study. In this observational study, patients undergoing RALP had less risk of erectile dysfunction at 12 months. There was no difference in urinary incontinence at 12 months.

We also found several meta-analyses. $\frac{8-18}{1}$ None of these found any difference in mortality or other cancer-related outcomes between RALP and RRP. With regards to the complications of urinary incontinence and sexual dysfunction, results were mixed, with some analyses finding a modest benefit to robotic surgery, and some analyses finding no difference. The Cochrane analysis was the only analysis that looked exclusively at randomized trials and found no difference in either complication rate. $\underline{\underline{12}}$

Overall, we found the literature supporting RALP to be lacking overall. Since most of the studies are cohort studies, they are at high risk of indication and recall bias. There is only one randomized control trial. Somewhat alarming was the amount of meta-analyses that have been performed; this can easily give the illusion that there is more and stronger evidence than there actually is. It was important for us to refocus on the primary literature to assess the strength of the literature overall.

Even with this ambiguity in the literature, RALP has become the more popular surgical approach with an understanding that there is no strong evidence to suggest that it is superior in terms of oncologic or functional outcomes.

\section{Informed Consent}

\author{
Flesch-Kincaid Grade Level for the following passage is 5.8.
}


LEE H, AHLGREN B. Informed Consent: Outcomes of robotic-assisted laparoscopic prostatectomy versus open prostatectomy in surgical intervention of localized prostate cancer. Clin. Res. Prac. 2019 Mar 26;5(1):eP1923. doi: $10.22237 / \mathrm{crp} / 1553558460$
Clinical Research in Practice

The Journal of Team Hippocrates

VOL 5 ISS 1 / eP1923 / MARCH 26, 2019 doi: $\underline{10.22237 / \mathrm{crp} / 1553558460}$

"We think we should take care of the cancer sooner rather than later. Your cancer is a medium grade and your PSA has risen. We think your cancer might spread. There are a few ways we could stop the cancer. We think surgery is the safe option for long term control of the cancer.

"We like to recommend a robotic procedure for patients. You said that your friends also had this cancer but had an open surgery. I will explain what is different between the two types.

"I went through the studies over the last 10 years to find an answer to your question. Unfortunately, it is still unclear which surgery is better. Also, the quality of the studies was not the best. What most studies found was that one type of surgery is not better than the other to stop the cancer. Both types have good cure rates in cancer similar to yours.

"Since this is a big surgery, there are some complications that we can't stop. These include bladder and sexual problems. For healthy people like you, these problems usually improve over time. Some studies show improved sexual function with robotic surgery. However, the best study did not. No studies showed long-term differences in bladder problems.

"The main benefit of the robotic surgery is in the short term. Most studies show that there was less bleeding and fewer blood transfusions with the robot. Also, patients usually go home in a day or two. The open surgery patients usually stay in the hospital longer. Due to these factors, we think that the robotic surgery may be the better option.

"Overall, both procedures do a great job to stop the cancer. There is not much high-quality data showing that one is better than the other. Most people think that the robot is better in the short term. Our group is most experienced with robotic surgery. That is why we would recommend this surgery to you. I would like to know what you think so we can decide together what the best option would be for you."

\section{References}

1. Coughlin GD, Yaxley JW, Chambers SK, et al. Robot-assisted laparoscopic prostatectomy versus open radical retropubic prostatectomy: 24-month outcomes from a randomised controlled study. Lancet Oncol. 2018;19(8):1051-1060. doi: 10.1016/S1470-2045(18)30357-7

2. Yaxley JW, Coughlin GD, Chambers SK, et al. Robot-assisted laparoscopic prostatectomy versus open radical retropubic prostatectomy: early outcomes from a randomised controlled phase 3 study. Lancet. 2016;388(10049):1057-1066. doi: 10.1016/S0140-6736(16)30592-X

3. Wei JT, Dunn RL, Litwin MS, Sandler HW, Sanda MG. Development and validation of the expanded prostate cancer index composite (EPIC) for comprehensive assessment of health-related quality of life in men with prostate cancer. Urology. 2000 Dec;56(6):899-905. doi: 10.1016/S0090-4295(00)00858-X

4. Rosen RC, Riley A, Wagner G, Osterloh IH, Kirkpatrick J, Mishra A. The international index of erectile function (IIEF): a multidimensional scale for assessment of erectile dysfunction. Urology. 1997 Jun;49(6):822-830. doi: 10.1016/S00904295(97)00238-0

5. Hu JC, O'Malley P, Chughtai B, et al. Comparative Effectiveness of Cancer Control and Survival after Robot-Assisted versus Open Radical Prostatectomy. J Urol. 2017;197(1):115-121. doi: 10.1016/j.juro.2016.09.115

6. O'Neil B, Koyama T, Alvarez J, et al. The Comparative Harms of Open and Robotic Prostatectomy in Population Based Samples. J Urol. 2016;195(2):321-329. doi: 10.1016/j.juro.2015.08.092

7. Haglind E, Carlsson S, Stranne J, et al. Urinary Incontinence and Erectile Dysfunction After Robotic Versus Open Radical Prostatectomy: A Prospective, Controlled, Nonrandomised Trial. Eur Urol. 2015;68(2):216-225. doi: 10.1016/j.eururo.2015.02.029

8. Ficarra V, Novara G, Ahlering TE, et al. Systematic review and meta-analysis of studies reporting potency rates after robotassisted radical prostatectomy. Eur Urol. 2012;62(3):418-430. doi: 10.1016/j.eururo.2012.05.046 
LEE H, AHLGREN B. Informed Consent: Outcomes of robotic-assisted laparoscopic prostatectomy versus open prostatectomy in surgical intervention of localized prostate cancer. Clin. Res. Prac. 2019 Mar 26;5(1):eP1923. doi: $10.22237 / \mathrm{crp} / 1553558460$
Clinical Research in Practice The Journal of Team Hippocrates

VOL 5 ISS 1 / eP1923 / MARCH 26, 2019 doi: $10.22237 / \mathrm{crp} / 1553558460$

9. Ficarra V, Novara G, Rosen RC, et al. Systematic review and meta-analysis of studies reporting urinary continence recovery after robot-assisted radical prostatectomy. Eur Urol. 2012;62(3):405-417. doi: 10.1016/i.eururo.2012.05.045

10. Ficarra V, Sooriakumaran P, Novara G, et al. Systematic review of methods for reporting combined outcomes after radical prostatectomy and proposal of a novel system: the survival, continence, and potency (SCP) classification. Eur Urol. 2012;61(3):541-548. doi: 10.1016/i.eururo.2011.11.042

11. Health Quality Ontario. Robotic Surgical System for Radical Prostatectomy: A Health Technology Assessment. Ont Health Technol Assess Ser. 2017;17(11):1-172.

12. Ilic D, Evans SM, Allan CA, Jung JH, Murphy D, Frydenberg M. Laparoscopic and robot-assisted vs open radical prostatectomy for the treatment of localized prostate cancer: a Cochrane systematic review. BJU Int. 2018;121(6):845-853. doi: 10.1111/bju.14062

13. Moran PS, O'Neill M, Teljeur C, et al. Robot-assisted radical prostatectomy compared with open and laparoscopic approaches: a systematic review and meta-analysis. Int J Urol. 2013;20(3):312-321. doi: $10.1111 /$ iju.12070

14. Novara G, Ficarra V, Mocellin S, et al. Systematic review and meta-analysis of studies reporting oncologic outcome after robotassisted radical prostatectomy. Eur Urol. 2012;62(3):382-404. doi: 10.1016/i.eururo.2012.05.047

15. Novara G, Ficarra V, Rosen RC, et al. Systematic review and meta-analysis of perioperative outcomes and complications after robot-assisted radical prostatectomy. Eur Urol. 2012;62(3):431-452. doi: 10.1016/i.eururo.2012.05.044

16. Pan XW, Cui XM, Teng JF, et al. Robot-Assisted Radical Prostatectomy vs. Open Retropubic Radical Prostatectomy for Prostate Cancer: A Systematic Review and Meta-analysis. Indian J Surg. 2015;77(Suppl 3):1326-1333. doi: 10.1007/s12262-014-1170-y

17. Tewari A, Sooriakumaran P, Bloch DA, Seshadri-Kreaden U, Hebert AE, Wiklund P. Positive surgical margin and perioperative complication rates of primary surgical treatments for prostate cancer: a systematic review and meta-analysis comparing retropubic, laparoscopic, and robotic prostatectomy. Eur Urol. 2012;62(1):1-15. doi: 10.1016/i.eururo.2012.02.029

18. Vora AA, Marchalik D, Kowalczyk KJ, et al. Robotic-assisted prostatectomy and open radical retropubic prostatectomy for locallyadvanced prostate cancer: multi-institution comparison of oncologic outcomes. Prostate Int. 2013;1(1):31-36. doi: $\underline{10.12954 / \mathrm{PI} .12001}$ 